\title{
Accelerated ecotoxicity of photoreactive nanoparticles on Moina macrocopa
}

\author{
Sun-Hwa Nam, Yu-Jin Shin, Youn-Joo An \\ Department of Environmental Health Science, Konkuk University, Seoul, Korea
}

\begin{abstract}
Zinc oxide nanoparticles (ZnO NPs) and titanium dioxide nanoparticles ( $\mathrm{TiO}_{2} \mathrm{NPs}$ ) are well known as photoreactive nanoparticles (NPs). Various phototoxicities of ZnO NPs

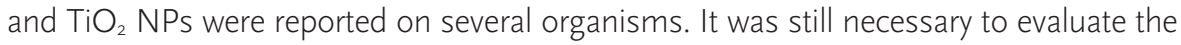
toxicity of photoreactive $\mathrm{ZnO} N \mathrm{NS}_{\mathrm{s}}$ and $\mathrm{TiO}_{2} \mathrm{NPs}$ due to species-specific effects under various irradiation conditions. We compared the acute toxicity of Moina macrocopa under visible, ultraviolet (UV) A, and B irradiations, according to the Organization for Economic Cooperation and Development guidelines for the testing of chemicals (Test No. 202). The sensitivity of $\mathrm{ZnO} N P s$ for $M$. macrocopa was $U V B>U V A>$ visible light irradiation. There were no significant lethal and immobile effects of $\mathrm{TiO}_{2} \mathrm{NPS}$ on juveniles under all irradiations and in the tested concentrations of $\mathrm{TiO}_{2}$ NPs. Photoreactive NPS have a potential and accelerated toxicity on organisms in the ambient environments.
\end{abstract}

\author{
Correspondence: Youn-Joo An \\ Department of Environmental Health \\ Science, Konkuk University, 120 \\ Neungdong-ro, Gwangjin-gu, Seoul 05029 \\ Korea \\ E-mail: anyjoo@konkuk.ac.kr \\ Received: December 6, 2016 \\ Accepted: February 10, 2017 \\ Published: March 22, 2017 \\ This article is available from: http://e-eht.org/
}

Keywords: Moina macrocopa, Phototoxicity, Titanium dioxide nanoparticles, Ultraviolet, Zinc oxide nanoparticles

\section{INTRODUCTION}

Zinc oxide nanoparticles ( $\mathrm{ZnO} \mathrm{NPs}$ ) and titanium dioxide nanoparticles $\left(\mathrm{TiO}_{2} \mathrm{NPs}\right)$, well known as photoreactive nanoparticles (NPs), are increasingly found in personal care products and distributed in the environment due to their easy biodegradability $[1,2]$. In prior literature, under ultraviolet (UV) irradiation, the increased phototoxicity of $\mathrm{ZnO} N \mathrm{NPs}$ and $\mathrm{TiO}_{2} \mathrm{NPs}_{\text {on }}$ fish (Oryzias latipes and Danio rerio), waterflea (Daphnia magna and Daphnia similis), nematodes (Caenorhabditis elegans), amphipod (Hyalella azteca), frogs (Xenopus laevis), and bacteria (Escherichia coli and Bacillus subtilis) was reported [2-9], while no significant phototoxicity of $\mathrm{ZnO} N \mathrm{NP}$ and $\mathrm{TiO}_{2} \mathrm{NPs}_{\mathrm{N}}$ on fish (Danio rerio), waterflea (D. magna), and algae (Pseudokirchneriella subcapitata and Desmodesmus subpicatus) $[1,10,11]$ was reported. It was still necessary to evaluate the toxicity of photoreactive $\mathrm{ZnO}$ NPs and $\mathrm{TiO}_{2}$ NPs due to species-specific effects under various irradiation conditions. However, the limited toxicity data of photoreactive $\mathrm{ZnO}$ NPs and $\mathrm{TiO}_{2} \mathrm{NPs}$ on waterflea (especially, D. magna or D. similis) exist. Therefore, it is requisite to expand various waterflea in order to assess the toxicity of photoreactive $\mathrm{ZnO} N \mathrm{Ns}$ and $\mathrm{TiO}_{2}$ NPs. Moina macrocopa is a representative Korean native species and used to assess ecotoxicity in various literatures.

\section{METHODS}

\section{Test Chemicals}

$\mathrm{ZnO}$ NPs (particle size $<100 \mathrm{~nm}$ ) and $\mathrm{TiO}_{2} \mathrm{NPs}$ (particle size $21 \mathrm{~nm}, \mathrm{P} 25$, white powder form) were purchased from Sigma-Aldrich (St. Louis, MO, USA) and Evonik Degussa (Bitterfeld-Wolfen, Germany), in a white powder form. A field emission-transmission electron microscope (FE-TEM; JEM2200FS, JEOL, Tokyo, Japan) was used to measure the morphology of the NPs. A particle size analyzer (UPA-150, Microtrac, Montgomeryville, PA, USA) was used to measure the specific surface area of the NPs. Particle size distributions of hydrodynamic diameters and zeta potential of $10 \mathrm{mg} / \mathrm{L} \mathrm{ZnO} N \mathrm{Ns}$ and $\mathrm{TiO}_{2} \mathrm{NPs}$ suspended in deionized water (DW) and M4 medium [7] were measured using an electrophoretic light scattering spectropho- 
tometer (ELS-8000, Otsuka Electronics Co., Osaka, Japan). A UV/Vis spectrophotometer (Libra S32 PC, Biochrom Ltd., Cambridge, UK) was used to observe the UV absorption spectra of $10 \mathrm{mg} / \mathrm{L} \mathrm{ZnO} \mathrm{NPs} \mathrm{and} \mathrm{TiO}_{2}$ NPs suspended in M4 medium at 10 minutes intervals for 60 minutes.

\section{Test Organism}

M. macrocopa was obtained from the Korea Institute of Toxicology (Daejeon, Korea). Cultures of test species were kept in M4 medium at $22 \pm 1^{\circ} \mathrm{C}$, respectively, with a photoperiod of 16:8 hours (light: dark). Green algae P. subcapitata was provided daily as a food source, with the concentration of $2 \times 10^{4}$ cells/ $\mathrm{mL}$. Neonates (less than 24 hours) were used for acute toxicity testing.

\section{Phototoxicity Test}

Stock solutions of $100 \mathrm{mg} / \mathrm{L}$ test NPs dispersed in M4 medium were vigorously shaken by hand and sonicated for $10 \mathrm{~min}$ utes at $40 \mathrm{kHz}$ in a water bath sonicator (Powersonic 420, Hwashin Technology, Seoul, Korea). Serial exposure solutions $(0,1,2,3,4$, and $5 \mathrm{mg} / \mathrm{L}$ for ZnO NPs and 0, 1, 3, 5, and $10 \mathrm{mg} /$ $\mathrm{L}$ for $\mathrm{TiO}_{2} \mathrm{NPs}$ ) were diluted with M4 medium. At this time, ethylenediaminetetraacetic acid was excluded from the M4 medium to prevent the chelating effect [13]. Exposure solutions were placed in a photoreactor (1 LZC-4, Luzchem Research Inc., Ottawa, Canada) under a UV lamp for UV irradiation and in the incubator under standard fluorescent lamps for visible light irradiation, then irradiated for 20 minutes. The photoreactor has a UV lamp with a spectral distribution of 316 to $400 \mathrm{~nm}$ for UVA and 281 to $315 \mathrm{~nm}$ for UVB. The light intensity measured using a spectroradiometer (SPR 4001, Luzchem Research Inc.) was $8.2 \mathrm{~mW} / \mathrm{m}^{2}$ for UVA and $5.68 \mathrm{~mW} / \mathrm{m}^{2}$ for UVB.

The acute toxicity test was conducted according to the Organization for Economic Cooperation and Development (OECD) guidelines (No. 202) for chemical testing [12]. Tests were performed with $2 \mathrm{~mL}$ of exposure solution in a 24-well microplate (inner diameter $17 \mathrm{~mm} \times$ height $17 \mathrm{~mm}$, volume $3.8 \mathrm{~mL} /$ well). Each test unit contained 5 neonates, with 4 replicates. The test duration was set as 48 hours. Survival and mobilization were measured as toxicity endpoints. The microplate was incubated under the same conditions as that of pre-incubation.

\section{Nanoparticles Dissolution and Ion Toxicity}

To estimate the dissolution of $\mathrm{ZnO}$ NPs in M4 medium, minimum and maximum exposure concentrations of $\mathrm{ZnO}$ NPs were exposed to the same conditions as those of the phototoxicity test. At 0 and 48 hour, each exposure solution was filtered sequentially through 200-nm nylon membrane filters (Whatman,
Maidstone, UK) and 50-nm membrane filters (Millipore, Darmstadt, Germany). Zinc $(\mathrm{Zn})$ ion concentrations were then measured using inductively coupled plasma-atomic emission spectroscopy (Jobin Yvon, Longjumeau, France). To estimate the effect of $\mathrm{Zn}$ ions released from the $\mathrm{ZnO}$ NPs, ion toxicity test was carried out in a same way as that of the $\mathrm{ZnO}$ NPs toxicity test, with Zn chloride (Sigma-Aldrich) and exposure concentrations of $0,0.5,1$, and $2 \mathrm{mg} / \mathrm{L}$.

\section{Statistics}

Multiple comparisons were conducted using Dunnett's test and differences were considered statistically significant at $p<0.05$. Trimmed-Spearman-Karber program was used to calculate the lethal concentration at $50 \%\left(\mathrm{LC}_{50}\right)$ and effective concentration at 50\% $\left(\mathrm{EC}_{50}\right)$ values, and their corresponding $95 \%$ confidence limits.

\section{RESULTS}

Figure S1 (A and B) show the morphological TEM images of test NPs. Table S1 shows the specific surface area, mean hydrodynamic diameter, and zeta potential of $\mathrm{ZnO} N P s$ and $\mathrm{TiO}_{2}$ NPs dispersed in M4 medium and DW. The zeta potential indicates that $\mathrm{ZnO}$ NPs are incipiently unstable and $\mathrm{TiO}_{2} \mathrm{NPs}$ rapidly coagulate or flocculate in solution. The UV absorption spectra of $10 \mathrm{mg} / \mathrm{L} \mathrm{ZnO} \mathrm{NPs} \mathrm{and} 10 \mathrm{mg} / \mathrm{L} \mathrm{TiO}_{2}$ NPs suspended in $\mathrm{M} 4$ were determined at 10 -minute intervals for 60 minutes (Figure S1C-S1F). Both ZnO NPs and $\mathrm{TiO}_{2} \mathrm{NPs}$ absorbed light ( 320 to $400 \mathrm{~nm}$ ) and peaked at 370 to $380 \mathrm{~nm}$ for $\mathrm{ZnO}$ $\mathrm{NPs}$ and 330 to $340 \mathrm{~nm}$ for $\mathrm{TiO}_{2} \mathrm{NPs}$. The absorbance of $\mathrm{TiO}_{2}$ $\mathrm{NPs}$ was higher than that of $\mathrm{ZnO} N P s$, indicating that $\mathrm{TiO}_{2} \mathrm{NPs}$ more easily absorb light and react with it, relative to $\mathrm{ZnO} N P s$. The absorbance of $\mathrm{ZnO} N$ Ns and $\mathrm{TiO}_{2}$ NPs decreased as a function of increased irradiation time. Figure $\mathrm{S} 1(\mathrm{G}$ and $\mathrm{H})$ shows that the ions released from the $\mathrm{ZnO} N P s$ increased as a function of increased exposure concentrations. At 0 hour, the number of ions released from the $\mathrm{ZnO}$ NPs under UV irradiation was greater than that under visible light irradiation $(p<0.5)$.

Figure 1 (A and B) shows the survival and mobilization of juveniles at 48 hours of exposure to $\mathrm{ZnO} N \mathrm{NP}$ and $\mathrm{TiO}_{2} \mathrm{NPs}$, under either visible light or UV irradiation. Figure $1 \mathrm{C}$ shows the control juveniles. Figure 1 (D-I) shows the lethal juveniles exposed to ZnO NPs, while Figure 1 (G-I) shows the normal juveniles exposed to $\mathrm{TiO}_{2} \mathrm{NPs}$. At $5 \mathrm{mg} / \mathrm{L} \mathrm{ZnO}$ NPs, gut and appendages of juveniles were adsorbed by aggregates assumed as $\mathrm{ZnO}$ NPs (black particles in Figure 1F). Gut of all $\mathrm{TiO}_{2}$ NPstreated juveniles was occupied by aggregates assumed as $\mathrm{TiO}_{2}$ NPs (black particles in Figure 1G-1I). With exposure to $\mathrm{ZnO}$ 
Table 1. Toxicity values of $M$. macrocopa after exposure to $\mathrm{ZnO} \mathrm{NPs}$ and $\mathrm{TiO}_{2} \mathrm{NPs}$ using acute toxicity test

\begin{tabular}{|c|c|c|c|c|c|c|c|}
\hline \multirow{2}{*}{ Endpoints } & \multirow{2}{*}{ Exposure duration (hr) } & \multicolumn{3}{|c|}{ ZnO NPs } & \multicolumn{3}{|c|}{$\mathrm{TiO}_{2} \mathrm{NPS}$} \\
\hline & & Visible & UVA & UVB & Visible & UVA & UVB \\
\hline \multirow[t]{2}{*}{$\mathrm{LC}_{50}$} & 24 & $>5$ & $>5$ & $>5$ & $>10$ & $>10$ & $>10$ \\
\hline & 48 & $2.71(2.31,3.17)$ & $2.15(1.99,2.33)$ & $1.62(1.38,1.91)$ & $>10$ & $>10$ & $>10$ \\
\hline \multirow[t]{2}{*}{ EC50 (immobilization) } & 24 & $1.96(1.78,2.16)$ & $>5$ & $3.67(3.37,4.00)$ & $>10$ & $>10$ & $>10$ \\
\hline & 48 & $1.79(1.65,1.94)$ & $1.41(1.32,1.51)$ & $1.12(0.92,1.36)$ & $>10$ & $>10$ & $>10$ \\
\hline
\end{tabular}

ZnO NPs, zinc oxide nanoparticles; $\mathrm{TiO}_{2} \mathrm{NPs}$, titanium nanoparticles; UV, ultraviolet; $\mathrm{LC}_{50}$, lethal concentration at $50 \%$; $\mathrm{EC}_{50}$, effective concentration at $50 \%$.
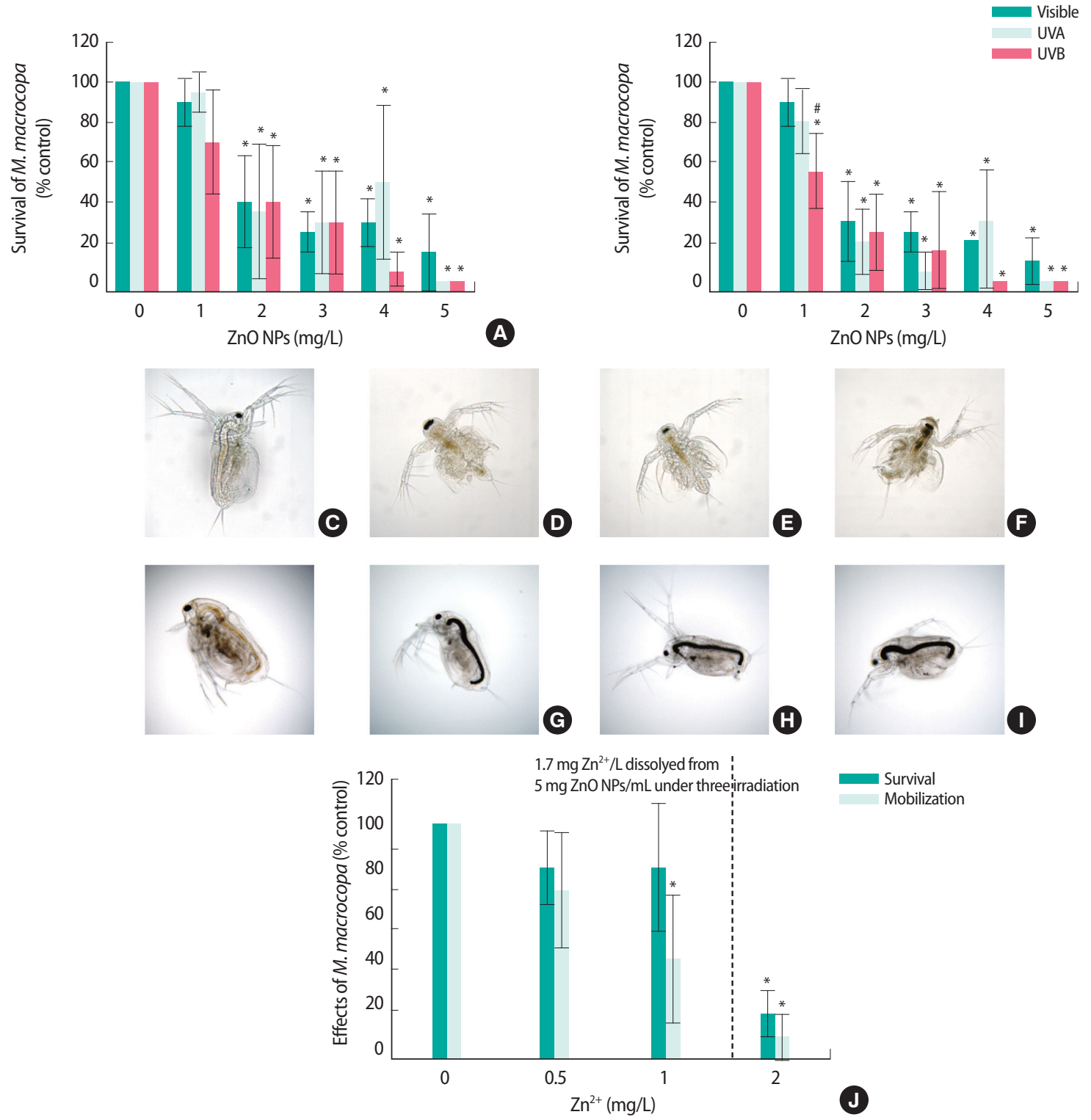

(

Figure 1. Effects of $\mathrm{ZnO}$ NPS, $\mathrm{TiO}_{2} \mathrm{NPS}$, and $\mathrm{Zn}$ ions under visible light, UVA, or UV irradiation on M. macrocopa. (A) Survival of ZnO NPs-treated M. macrocopa, (B) mobilization of Zn0 NPs-treated M. macrocopa, (C) control of M. macrocopa, (D-F) 1, 3, and 5 mg/L of Zn0 NPs-treated lethal M. macrocopa, respectively, (G-I) 1, 5, and $10 \mathrm{mg} / \mathrm{L}$ of $\mathrm{TiO}_{2}$ NPs-treated $\mathrm{M}$. macrocopa, respectively, and (J) effects of Zn ions-treated M. macrocopa. Zn0 NPs, zinc oxide nanoparticles; $\mathrm{TiO}_{2} \mathrm{NPS}$, titanium dioxide nanoparticles; $\mathrm{Zn}$, zinc; UV, ultraviolet. ${ }^{*} p<0.05$ : significant differences from visible light at the same exposure concentrations. ${ }^{*} p<0.05$ : significant differences from the control under visible light.

NPs, the survival and mobilization of juveniles were noticeably decreased from 2 to $5 \mathrm{mg} / \mathrm{L}$ NPs under all irradiation (Figure $1 \mathrm{~A}$ and $1 \mathrm{~B})$. At concentrations of $1 \mathrm{mg} / \mathrm{L} \mathrm{ZnO} \mathrm{NPs}, \mathrm{ZnO} \mathrm{NP}$ - treated juveniles under UVB irradiation exhibited significantly decreased mobilization compared with those under visible light irradiation $(p<0.05)$. According to 48 hours- $\mathrm{LC}_{50}$ and 48 
hours-EC $\mathrm{E}_{50}$ presented in Table 1, the sensitivity of $\mathrm{ZnO}$ NPs for M. macrocopa was UVB $>$ UVA > visible light irradiation. Meanwhile, there were no significant lethal and immobile effects of $\mathrm{TiO}_{2} \mathrm{NPs}$ on juveniles under all the irradiations, at any of the tested $\mathrm{TiO}_{2} \mathrm{NP}$ concentrations.

To assess the adverse effects of ions released from ZnO NPs, we conducted an ion toxicity assay $\left(0.5,1\right.$, and $\left.2 \mathrm{mg} \mathrm{Zn}^{2+} / \mathrm{L}\right)$ using $1.7 \mathrm{mg} \mathrm{Zn}^{2+} / \mathrm{L}$ released from the maximum concentrations of $\mathrm{ZnO}$ NPs under all the irradiations (Figure 1J). Zn ions induced mortality and immobilization of juveniles. Toxicity values for $\mathrm{Zn}$ ions were calculated as 1.38 (1.30 to 1.46$) \mathrm{mg} \mathrm{Zn}^{2+}$ / $\mathrm{L}$ for 48 hours-LC $\mathrm{L}_{50}$ and 0.79 (0.68 to 0.92$) \mathrm{mg} \mathrm{Zn}^{2+} / \mathrm{L}$ for 48 hours- $\mathrm{EC}_{50}$, respectively.

\section{DISCUSSION}

The absorbance of $\mathrm{ZnO}$ NPs and $\mathrm{TiO}_{2}$ NPs determined by $\mathrm{UV} /$ Vis spectrophotometer showed a decrease dependent on increased irradiation time. This is possibly due to the aggregation and dissolution of NPs. When $\mathrm{TiO}_{2} \mathrm{NPs}$ were re-sonicated for 10 minutes, the absorbance of $\mathrm{TiO}_{2} \mathrm{NPs}_{\text {increased (data not }}$ shown). However, the absorbance of $\mathrm{ZnO} \mathrm{NPs}$ was unaltered after re-sonication, probably indicating dissolution of the $\mathrm{ZnO}$ NPs. The ions released from the ZnO NPs showed increase dependent on increased exposure concentrations. In addition, the ions released from the $\mathrm{ZnO}$ NPs under UV irradiation were greater than under visible light irradiation $(p<0.5)$. This phenomenon may be due to the accelerated dissolution of $\mathrm{ZnO}$ NPs caused by UV irradiation [2,11], in the initial stages. In a previous study, Lee and An [11] and Shin et al. [2] reported the absorbance of $\mathrm{ZnO}$ NPs and $\mathrm{TiO}_{2} \mathrm{NPs}$ as a function of time until 1 hour. They reported the absorbance of $\mathrm{ZnO} N \mathrm{NP}$ and $\mathrm{TiO}_{2}$ NPs dispersed in OECD algal medium and M4 medium was decreased as a function of increased irradiation time, as observed in this study.

UV irradiations induced more serious effects of ZnO NPs on M. macrocopa compared to visible light irradiation, according to toxicity values presented in Table 1 . Since $1.7 \mathrm{mg} \mathrm{Zn}^{2+} / \mathrm{L}$ released from maximum concentrations of $\mathrm{ZnO}$ NPs included in 1 to $2 \mathrm{mg} \mathrm{Zn}^{2+} / \mathrm{L}$, the ions released from $\mathrm{ZnO} N$ Ps is may be induced mortality and immobilization of juveniles, described in Figure 1J. Similar to what was found in this study, the increased dissolution of $\mathrm{ZnO}$ NPs was shown in various exposure solutions $[2,3,14,15]$. Therefore, the observed mortality and immobilization of juveniles were probably due to both the ZnO NPs and $\mathrm{Zn}$ ions released from the NPs. The different sensitivity of ZnO NPs on M. macrocopa under three irradiations may be caused by a dissolution rate of $\mathrm{ZnO}$ NPs in exposure solutions.
According to Figure $1 \mathrm{G}$ and $1 \mathrm{H}$, more ions were released from the $\mathrm{ZnO}$ NPs under UV irradiation than under visible light irradiation, just after pre-irradiation of UVA or UVB (at 0 hour). At 48 hour, there were no significant differences in dissolution levels between visible and UV irradiation. The promoted toxicity of $\mathrm{ZnO}$ NPs under UV irradiation is shown in the bacterial growth inhibition and mortality of nematode [3,4]. According to a prior study, $\mathrm{Zn}$ ions induced the inhibition of survival and reproduction of D. magna [16]. Zn ions inhibited calcium uptake and the production of hypocalcaemia in D. magna, thereby inhibiting movement, filtration rate, food uptake, available energy, growth, and reproduction. Therefore, the different mortality and immobilization of juveniles was probably due to the accelerated dissolution of $\mathrm{ZnO}$ NPs just after pre-irradiation by UV light, compared to visible light irradiation.

Under UV irradiation, ZnO NPs show bioavailable dissolution to decrease the survival and mobilization of M. macrocopa. Our results suggest that the photoreactive NPs, under solar light during daytime, have a potential and accelerated toxicity on organisms in dark environments. Therefore, it is necessary to evaluate the altered toxicity of photoreactive NPs in various environments and investigate mechanisms for photoreactive NPs.

\section{ACKNOWLEDGEMENTS}

This research was supported by Basic Science Research Program through the National Research Foundation of Korea (NRF) funded by the Ministry of Science, ICT and Future Planning (2016R1A2B3010445). We thank the Korean Basic Science Institute (KBSI) for TEM, particle size analyzer, and ELS analyses.

\section{CONFLICT OF INTEREST}

The authors have no conflicts of interest associated with the material presented in this paper.

\section{ORCID}

Sun-Hwa Nam http://orcid.org/0000-0003-4633-296X

Youn-Joo An http://orcid.org/0000-0002-0193-1929

\section{REFERENCES}

1. Bar-Ilan O, Louis KM, Yang SP, Pedersen JA, Hamers RJ, Peterson $\mathrm{RE}$, et al. Titanium dioxide nanoparticles produce phototoxicity in the developing zebrafish. Nanotoxicology 2012;6(6):670-679.

2. Shin YJ, Nam SH, An YJ. Continuous ultraviolet irradiation increases the adverse effects of photoreactive nanoparticles on the early 
development of Oryzias latipes. Environ Toxicol Chem 2016; 35(5):1195-1200.

3. Kim SW, An YJ. Effect of $\mathrm{ZnO}$ and $\mathrm{TiO}_{2}$ nanoparticles preilluminated with UVA and UVB light on Escherichia coli and Bacillus subtilis. Appl Microbiol Biotechnol 2012;95(1):243-253.

4. Ma H, Kabengi NJ, Bertsch PM, Unrine JM, Glenn TC, Williams PL. Comparative phototoxicity of nanoparticulate and bulk $\mathrm{ZnO}$ to a free-living nematode Caenorhabditis elegans: the importance of illumination mode and primary particle size. Environ Pollut 2011;159(6):1473-1480.

5. Ma H, Brennan A, Diamond SA. Phototoxicity of TiO2 nanoparticles under solar radiation to two aquatic species: Daphnia magna and Japanese medaka. Environ Toxicol Chem 2012;31(7):16211629.

6. Marcone GP, Oliveira AC, Almeida G, Umbuzeiro GA, Jardim WF. Ecotoxicity of TiO2 to Daphnia similis under irradiation. J Hazard Mater 2012;211-212:436-442.

7. Clemente Z, Castro VL, Moura MA, Jonsson CM, Fraceto LF. Toxicity assessment of $\mathrm{TiO}_{2}$ nanoparticles in zebrafish embryos under different exposure conditions. Aquat Toxicol 2014;147:129-139.

8. Li S, Wallis LK, Ma H, Diamond SA. Phototoxicity of $\mathrm{TiO}_{2}$ nanoparticles to a freshwater benthic amphipod: are benthic systems at risk? Sci Total Environ 2014;466-467:800-808.

9. Zhang J, Wages M, Cox SB, Maul JD, Li Y, Barnes M, et al. Effect of titanium dioxide nanomaterials and ultraviolet light coexposure on African clawed frogs (Xenopus laevis). Environ Toxicol Chem
2012;31(1):176-183.

10. Hund-Rinke K, Simon M. Ecotoxic effect of photocatalytic active nanoparticles (TiO2) on algae and daphnids. Environ Sci Pollut Res Int 2006;13(4):225-232.

11. Lee WM, An YJ. Effects of zinc oxide and titanium dioxide nanoparticles on green algae under visible, UVA, and UVB irradiations: no evidence of enhanced algal toxicity under UV pre-irradiation. Chemosphere 2013;91(4):536-544.

12. Organization for Economic Cooperation and Development. OECD guidelines for the testing of chemicals: Test No. 202: Daphnia sp. acute immobilisation test; 2004 [cited 2017 Mar 10]. Available from: http://www.oecd-ilibrary.org/environment/test-no-202daphnia-sp-acute-immobilisation-test_9789264069947-en.

13. Huebert DB. Dyck BS, Shay JM. The effect of EDTA on the assessment of $\mathrm{Cu}$ toxicity in the submerged aquatic macrophyte, Lemna trisulca L. Aquat Toxicol 1993;24(3-4):183-194.

14. Kasemets K, Ivask A, Dubourguier HC, Kahru A. Toxicity of nanoparticles of $\mathrm{ZnO}, \mathrm{CuO}$ and $\mathrm{TiO} 2$ to yeast Saccharomyces cerevisiae. Toxicol In Vitro 2009;23(6):1116-1122.

15. Wang Z, Lee YH, Wu B, Horst A, Kang Y, Tang YJ, et al. Anti-microbial activities of aerosolized transition metal oxide nanoparticles. Chemosphere 2010;80(5):525-529.

16. Muyssen BT, De Schamphelaere KA, Janssen CR. Mechanisms of chronic waterborne $\mathrm{Zn}$ toxicity in Daphnia magna. Aquat Toxicol 2006;77(4):393-401. 
Environmental Health and Toxicology 2017;32:e2017007

Table S1. Physicochemical properties of $\mathrm{ZnO}$ NPs and $\mathrm{TiO}_{2} \mathrm{NPS}$

\begin{tabular}{|c|c|c|}
\hline Properties & Zn0 NPs & $\mathrm{TiO}_{2} \mathrm{NPs}$ \\
\hline Manufacturer & Sigma-Aldrich & Evonik Degussa \\
\hline Crystal structure ${ }^{a}$ & - & Anatase $72.6 \%$, Rutile $18.4 \%$, Amorphous 9\% \\
\hline Surface coating ${ }^{\mathrm{a}}$ & No & No \\
\hline \multicolumn{3}{|c|}{ Mean hydrodynamic diameter $(\mathrm{nm})^{\mathrm{b}}$} \\
\hline Deionized water & $211 \pm 11$ & $354 \pm 15$ \\
\hline M4 medium & $622 \pm 30$ & $1389 \pm 53$ \\
\hline \multicolumn{3}{|l|}{ Zeta potential $(\mathrm{mV})^{\mathrm{b}}$} \\
\hline Deionized water & $-13.3 \pm 1.1$ & $-2.0 \pm 1.4$ \\
\hline M4 medium & $-10.1 \pm 2.4$ & $-0.4 \pm 0.3$ \\
\hline Specific surface area $\left(\mathrm{m}^{2} / \mathrm{g}\right)^{c}$ & $12.0 \pm 0.0$ & $55.0 \pm 0.4$ \\
\hline
\end{tabular}

ZnO NPs, zinc oxide nanoparticles; $\mathrm{TiO}_{2} \mathrm{NPs}$, titanium dioxide nanoparticles.

aSupplied from the manufacturer.

${ }^{b}$ Measured by electrophoretic light scattering spectrophotometer .

'Measured by particle size analyzer. 

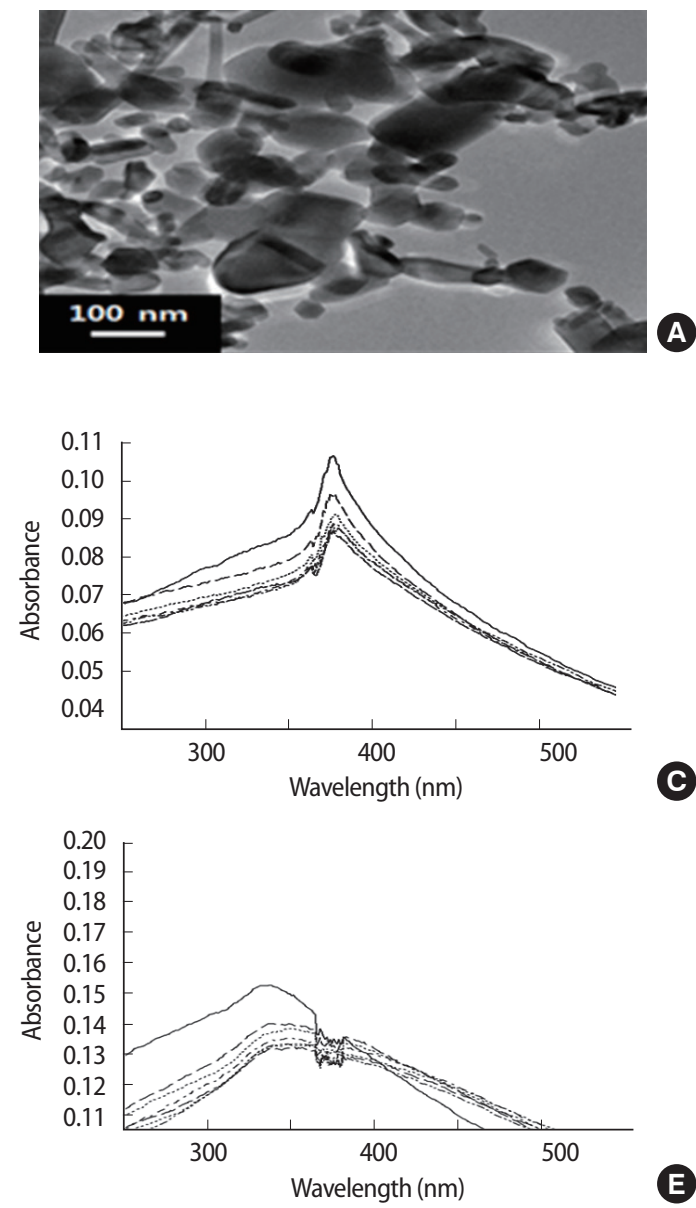

C

E

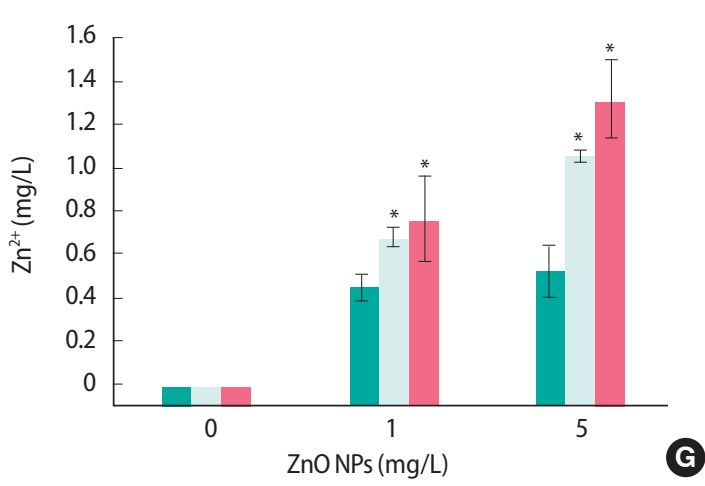

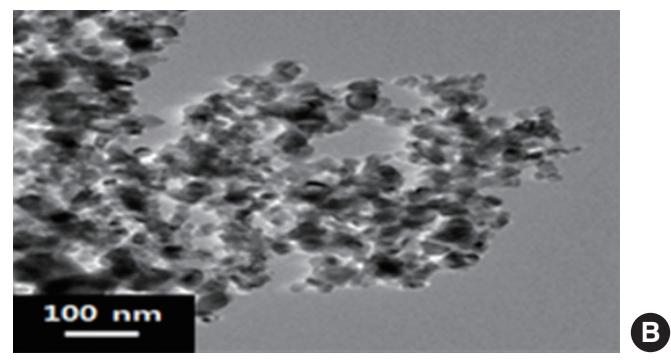
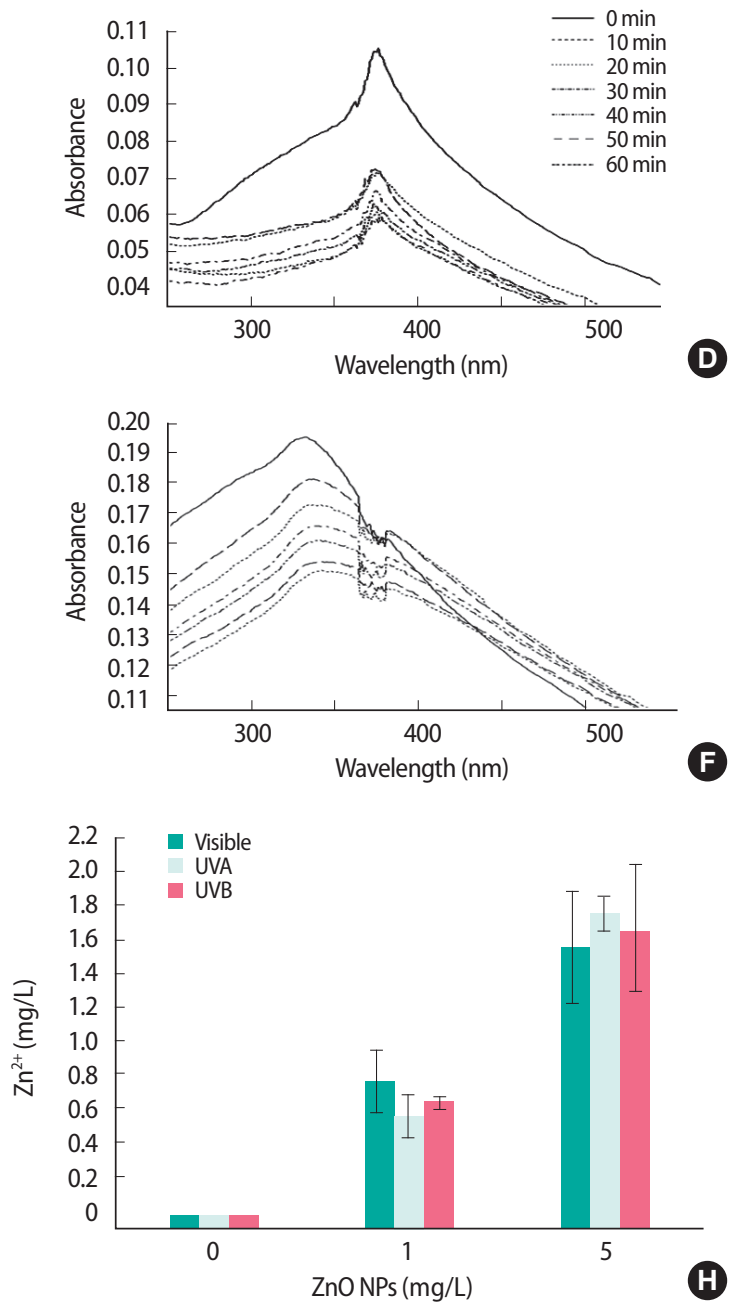

Figure S1. Physicochemical characterization of $\mathrm{ZnO} N P s$ and $\mathrm{TiO}_{2} \mathrm{NPs}$ and $\mathrm{Zn}$ ions released from the exposure concentration of $\mathrm{ZnO}$ NPs dispersed in M4 medium ( $\mathrm{A}$ and $\mathrm{B}$ ). Transmission electron microscope images of $\mathrm{ZnO} N \mathrm{NP}$ and $\mathrm{TiO}_{2} \mathrm{NPs}$ (C and D). Absorption spectra of ZnO NPs under UVA and UVB (E and

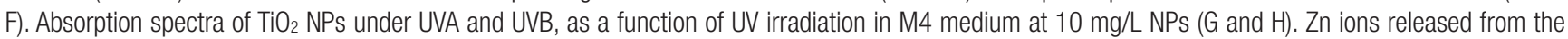
exposure concentrations of ZnO NPs at 0 and 48 hours. ZnO NPs, zinc oxide nanoparticles; $\mathrm{TiO}_{2}$ NPs, titanium dioxide nanoparticles; Zn, zinc; UV, ultraviolet. ${ }^{*} p<0.05$ significant differences from visible light at the same exposure concentrations. 